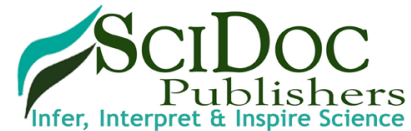

International Journal of Forensic Science \& Pathology (IJFP)

ISSN 2332-287X

\title{
Hanging Suicides in Himachal Pradesh: An Analysis of Forensic Cases
}

Research Article

Pal SK ${ }^{1 *}$, Sharma A $A^{2}$, Sehgal A ${ }^{1}$, Kaushik N ${ }^{3}$, Rana A

${ }^{1}$ Biology \& Serology Division, Regional Forensic Science Laboratory, Northern Range, Dharamshala, Himachal Pradesh, India.

${ }^{2}$ Directorate of Forensic Science, Shimla Hills, Junga, Himachal Pradesh, India.

${ }^{3}$ Biology \& Serology Division, State Forensic Science Laboratory, Himachal Pradesh, Shimla Hills, Junga, India.

\section{Abstract}

Hangings is one of the preferred modes of committing suicide nowadays. Cultural, social and psychological aspects have the direct role in the causation of suicide. The present study highlights the various contributory and precipitating factors associated with the suicidal hanging.

Objective: To investigate the socio-demographic profile, motives/modes and incidence of other factors associated with hanging.

Materials and Methods: The study was conducted on 122 cases of suicidal hanging at Regional Forensic Science Laboratory, Northern Range, Dharamshala from September 2009 to December, 2014.

Results: Males (68.85\%) predominate females (31.15\%). Highest incidence was found in the 21-40 age group (66.38\%). Most of the victims were married (70.49\%) and belonged to the Hindu religion (95.08\%). 15.55\% victims were educated and in most of the cases $(82.78 \%$ ) data was not available. According to occupation, $32.78 \%$ cases belonged to housewives followed by students in $13.11 \%$ cases. $90.16 \%$ victims hailed from rural zones. Physical illness, psychiatric illness/mental disorder were the most common factors in $36.06 \%$ cases followed by quarrel with spouse in $11.47 \%$ cases. $36.88 \%$ cases were reported in the month of January to April. Most of the people $(74.59 \%)$ preferred indoor closed locations. Rope $(43.44 \%)$ was the most commonly used ligature material followed by chunni/dupatta $(40.16 \%)$. Iron guider/beams were used for hanging in 39.34\% cases followed by ceiling fan and ceiling hook in $36.06 \%$ cases. Dribbling of saliva was present in $64.75 \%$ cases. Seminal discharge was observed in $30.32 \%$ cases and urinary incontinence in $42.62 \%$ cases. Cyanosis on mouth, tongue and face was noticed in $51.63 \%$, ecchymosis in $36.06 \%$ and petechial haemorrhages in $46.72 \%$ cases.

Conclusions: The study concludes that young population is more at risk. Most of the people preferred indoor closed locations for committing suicides. Males were more likely to commit suicide by hanging. Physical, psychiatric, mental disorder, quarrel with spouse and drug addiction were major causative factors.

Keywords: Hanging; Ligature; Suicide; Neck; Place.

\section{Introduction}

Hanging is one of the most common modes of committing suicide worldwide which causes instant death. Hanging is a form of violent mechanical asphyxia death in which force applied to the neck is derived from a gravitational drag of the weight of the body or part of the body [1]. It is almost always suicidal or accidental, the former being by far most common. Hanging is one of the popular modes of suicides in India since time immemorial for its simplicity, availability of objects and in terms of efficacy.
It produces painless death for the victims and there is no cost involvement other than that of ligature material. Hanging is particularly lethal method of suicide with an estimated fatality rate of over 70\% [2]. Many cultural and socio-economic factors are responsible for the causation of hangings. Rapid urbanization, industrialization and emerging family systems are resulting in social upheaval and distress [3].

Asphyxia in hanging results from compression or constriction of the neck structures by a noose or other kind of structure around

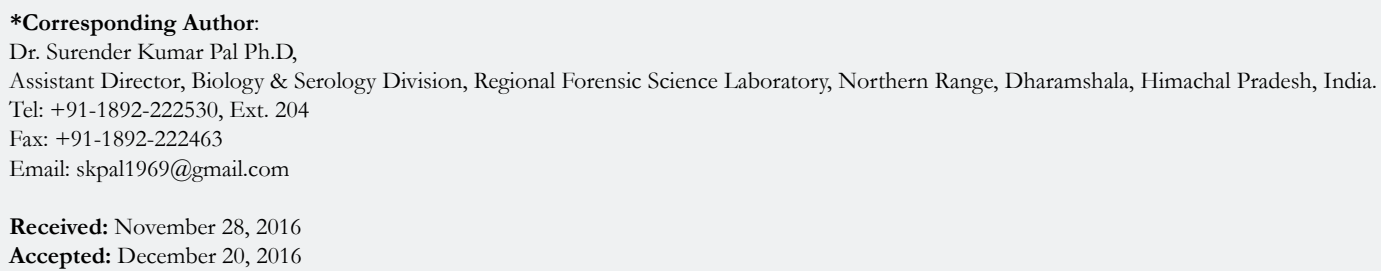

Copyright: Pal SK 2016. This is an open-access article distributed under the terms of the Creative Commons Attribution License, which permits unrestricted use, distribution and reproduction in any medium, provided the original author and source are credited. 
the neck tightened by the weight of the body [4]. It accounts for more than a million deaths annually making it one of the 10 leading causes of death in the world [5]. Tendency of an individual to commit suicide is deeply personal and individual act. Suicidal behavior is determined by mental condition of the individual and social factors [6]. The emerging phenomenon of cyber-suicide in the internet era is a further cause for concern [7, 8], also because the uses of new methods of suicide are associated with epidemic increases in overall suicide rates [9]. Suicides are often committed because of financial problems and difficulty in social relationship play an important role in this act [10]. Suicide rates in the world mainly in developing countries have increased about $60 \%$ in the past 50 years. A significant amount of suicides occur in Asia, which include about $60 \%$ of the suicides. According to the WHO reports, China, India and Japan are included in approximately $4 \%$ of all world suicides [11]. The National Crime Records Bureau (NCRB) 2014 reports revealed that on an average more than one lakh persons committed suicide every year in India during the decadal period from 2004 to 2014. The highest incidents of suicides were reported in Maharashtra (12.4\%) followed by Tamilnadu (12.2\%) and West Bengal (10.9\%). The NCRB report stated that the incidence of suicide by hanging increasing every year in India. Puducherry continued to report high suicidal rates since last three years in India 36.8\% in 2012, 35.6\% in 2013 and $40.4 \%$ in 2014 [12].

The seriousness and scope of suicide has led the WHO to call for an expansion of data collection on the prevalence of and risk factors for suicide and nonfatal suicidal behaviour to aid in the planning of public-health strategies and health-care policies and in the monitoring of behavioural responses to policy changes and prevention efforts [13].

Himachal Pradesh recorded a $16.2 \%$ increase in suicide cases in 2014. As many as 644 persons, including 396 men and 248 women committed suicide. Of these, $17.7 \%$ were unemployed youth. Not only unemployed but also self-employed persons committed suicide in 2014 [14]. The present study was undertaken with the objective to project the magnitude of problem, socio-demographic and incidence of other factors associated with hanging.

\section{Material and Methods}

\section{Study Design}

This retrospective study was conducted in Biology and Serology Division of Regional Forensic Science Laboratory, Northern Range, Dharamshala, Himachal Pradesh, India. It was based on the cases of suicide by hanging received for examination from three districts of northern range of Himachal Pradesh during the year September 2009 - December, 2014. A total of 122 cases were examined over a period of five years.

\section{Data Collection}

The detailed information regarding cause of death, socio-demographic factors (age, sex, religion, marital status, place of residence, profession, place of incidence etc.) and other associated information was gathered from police forwarding letter/records, inquest reports, first information reports, postmortem examination reports, and results of forensic laboratory examination of the exhibits. The details were entered on a semi-structured questionnaire developed by the researchers after a review of the related literature.

\section{Data Analysis}

Available data was put into the master-chart, feed into the computer in Excel worksheet and then analysed.

\section{Results}

\section{Demographic Details}

A total of 122 cases of suicidal hanging were reported within the period between 2009 and 2014. Sex distribution revealed 84 $(68.85 \%)$ males and $38(31.15 \%)$ females indicating a male: female ratio of nearly 2: 1 . Most common affected age group was between $21-30$ years in $50(40.98 \%)$ cases followed by $31-40$ years in $31(25.40 \%), 11-20$ years in $15(12.29 \%), 41-50$ years in 14 $(11.47 \%), 51-60$ years in $9(7.37 \%), 61-70$ years in $2(1.63 \%)$ cases and above 70 years in $1(0.82 \%)$ case. The youngest victim was 14 years and oldest was 95 years of age. 116 (95.08\%) victims were Hindus followed by Muslims in $2(1.63 \%)$ and Buddhists in $2(1.63 \%)$ cases, Sikh in $1(0.82 \%)$ and Christian in $1(0.82 \%)$ case. Married victims contributed to $86(70.49 \%)$ and unmarried to $36(29.50 \%) .110(90.16 \%)$ hanging cases were reported from rural area and $12(9.83 \%)$ from urban area. In 101 (82.78\%) cases, data regarding education status of the victim was not available, however $19(15.55 \%)$ cases were from the literate group, whereas $02(1.63 \%)$ were illiterate. $40(32.78 \%)$ hanging cases belonged to housewives followed by students in $16(13.11 \%)$, skilled labourer in $15(12.29 \%)$, employed in $13(10.65 \%)$, agriculture labourer in $13(10.65 \%)$, unemployed in $10(8.19 \%)$, business in $9(7.37 \%)$, retired from job/service in $3(2.45 \%)$ and farmer in $3(2.45 \%)$ cases [Table-1].

\section{Season Wise Incidence and Place of Hanging}

$45(36.88 \%)$ cases were reported in the months of January to April followed by 39 (31.96\%) in May to August and 38 (31.14\%) in September to December almost in equal distribution [Table-2]. $91(74.59 \%)$ victims preferred indoor sites (own house, hotel, hostel, shop, office, cow shed and rented house) for hanging as compared to outdoor sites (forest, rivulet/nullah, fields, and orchards) in 31 (25.41\%) [Table-3].

\section{Precipitating/Causative Factors}

The information about physical illness, psychiatric illness/mental disorder and other precipitating factors were mentioned in the docket submitted by the investigating agencies. In $44(36.06 \%)$ cases, the causative factors of committing suicide were physical illness, psychiatric illness/mental disorder followed by quarrel with spouse in 14 (11.47\%), drug addiction in 11 (9.01\%), dowry dispute/demand in $9(7.37 \%)$, family problems in 8 (6.55\%), poverty/economic distress in $2(1.63 \%)$, property dispute/loan in 2 $(1.63 \%)$, quarrel with in-laws in $2(1.63 \%)$, bereavement/death of dear person in $2(1.63 \%)$ cases and unemployment/frustration in life and failure in love/love affairs in 1 case each. In $26(21.31 \%)$ cases, the cause was not known [Table-4]. 
Table 1. Socio-Demographic Characteristics of Hanging.

\begin{tabular}{|c|c|c|}
\hline Characters & No. of cases & Percentage \\
\hline \multicolumn{3}{|c|}{ Sex } \\
\hline Male & 84 & $68.85 \%$ \\
\hline Female & 38 & $31.15 \%$ \\
\hline \multicolumn{3}{|c|}{ Age group (years) } \\
\hline Below 10 & 0 & $0 \%$ \\
\hline $11-20$ & 15 & $12.29 \%$ \\
\hline $21-30$ & 50 & $40.98 \%$ \\
\hline $31-40$ & 31 & $25.40 \%$ \\
\hline $41-50$ & 14 & $11.47 \%$ \\
\hline $51-60$ & 09 & $7.37 \%$ \\
\hline $61-70$ & 02 & $1.63 \%$ \\
\hline Above 70 & 01 & $0.82 \%$ \\
\hline \multicolumn{3}{|c|}{ Religion } \\
\hline Hindu & 116 & $95.08 \%$ \\
\hline Muslim & 02 & $1.63 \%$ \\
\hline Buddhist & 02 & $1.63 \%$ \\
\hline Sikh & 01 & $0.82 \%$ \\
\hline Christian & 01 & $0.82 \%$ \\
\hline \multicolumn{3}{|c|}{ Marital status } \\
\hline Married & 86 & $70.49 \%$ \\
\hline Unmarried & 36 & $29.50 \%$ \\
\hline \multicolumn{3}{|l|}{ Residential status } \\
\hline Rural & 110 & $90.16 \%$ \\
\hline Urban & 12 & $9.83 \%$ \\
\hline \multicolumn{3}{|c|}{ Education } \\
\hline Illiterate & 02 & $1.63 \%$ \\
\hline Up to tenth standard/10+2 & 14 & $11.47 \%$ \\
\hline Graduate & 03 & $2.45 \%$ \\
\hline Diploma & 02 & $1.63 \%$ \\
\hline Not mentioned & 101 & $82.78 \%$ \\
\hline \multicolumn{3}{|c|}{ Occupation } \\
\hline Housewife & 40 & $32.78 \%$ \\
\hline Farmer & 03 & $2.45 \%$ \\
\hline Student & 16 & $13.11 \%$ \\
\hline Employed & 13 & $10.65 \%$ \\
\hline Business & 09 & $7.37 \%$ \\
\hline Unemployed & 10 & $8.19 \%$ \\
\hline Retired from job/service & 03 & $2.45 \%$ \\
\hline Skilled labourer & 15 & $12.29 \%$ \\
\hline Agriculture labourer & 13 & $10.65 \%$ \\
\hline
\end{tabular}

Table 2. Time of Year Among Hanging.

\begin{tabular}{|c|c|c|}
\hline Time of year & No. of cases & Percentage \\
\hline January to April & 45 & $36.88 \%$ \\
\hline May to August & 39 & $31.96 \%$ \\
\hline September to December & 38 & $31.14 \%$ \\
\hline
\end{tabular}


Table 3. Place of Hanging.

\begin{tabular}{|c|c|c|}
\hline Place of hanging & No. of cases & Percentage \\
\hline Indoor (own house, hotel, hostel, shop, office, cow shed, rented house) & 91 & $74.59 \%$ \\
\hline Outdoor (forest, rivulet/nullah, fields, orchards) & 31 & $25.41 \%$ \\
\hline
\end{tabular}

Table 4. Precipitating/Causative Factors for Hanging.

\begin{tabular}{|c|c|c|}
\hline Causative/trigger factors & No. of cases & Percentage \\
\hline Physical illness, Psychiatric illness/mental disorder & 44 & $36.06 \%$ \\
\hline Family problems & 08 & $6.55 \%$ \\
\hline Quarrel with spouse & 14 & $11.47 \%$ \\
\hline Poverty/economic distress & 02 & $1.63 \%$ \\
\hline Property dispute/loan & 02 & $1.63 \%$ \\
\hline Drug addiction & 11 & $9.01 \%$ \\
\hline Dowry dispute/demand & 09 & $7.37 \%$ \\
\hline Quarrel with in- laws & 02 & $1.63 \%$ \\
\hline Bereavement/death of dear person & 02 & $1.63 \%$ \\
\hline Unemployment/ frustration in life & 01 & $0.82 \%$ \\
\hline Failure in love/love affairs & 01 & $0.82 \%$ \\
\hline Unknown/cause not known & 26 & $21.31 \%$ \\
\hline
\end{tabular}

\section{Ligature Material used and Ligature Points}

Rope (synthetic and jute/sunn) was the most common ligature material used in $53(43.44 \%)$ cases followed by chunni/dupatta in $49(40.16 \%)$, nylon cloth/parna in $6(4.91 \%)$, shirt in $3(2.45 \%)$, muffler in $2(1.63 \%)$, electric wire/clutch wire in $2(1.63 \%)$ cases, plastic strap, salwar, towel, stole, niwar, rubber pipe and turban/ pagri in 1 case each [Table-5]. Most commonly used ligature point was iron guider in $29(23.77 \%)$ cases followed by ceiling fan in $28(22.95 \%)$, trees in $23(18.85 \%)$, beams in 19 (15.57\%), ceiling hook in $16(13.11 \%)$, ventilator in $3(2.45 \%)$, iron grill/rod in 2 $(1.63 \%)$ cases and stairs and window in 1 case each [Table-6].

\section{Post-Mortem Findings}

Ecchymosis was present in $44(36.06 \%)$, white glistening in 43 $(35.24 \%)$ and petechial haemorrhages in $57(46.72 \%)$ cases of hanging [Table-7]. Dribbling of saliva was present in $79(64.75 \%)$, protrusion of tongue in $79(64.75 \%)$, seminal emission in 37 $(30.32 \%)$, urinary incontinence in $52(42.62 \%)$ and faecal incontinence in $61(50.0 \%)$ cases. Blood from mouth and nostrils was found in $36(29.50 \%)$, cyanosis on mouth, tongue, face was noted in $63(51.63 \%)$ and clenching of teeth and fists was observed in $68(55.73 \%)$ cases of hanging [Table-8].

\section{Discussion}

Hanging is one of the most common causes of suicide deaths in India. In this study, majority of hanging deaths were contributed by males $(68.85 \%)$ followed by females $(31.15 \%)$ indicating a male: female ratio of about 2:1, which is consistent with observation of Kumar et al., [15] Udhayabanu et al., [16] and Momin et al., [17]. Rawat and Rodrigues [18] reported $78.22 \%$ cases of male and $21.78 \%$ cases of female with male to female ratio of approximately 3:1. Kumar et al., [19] reported male to female ratio of about 2.1:1. Studies in other parts of the world also showed male predominance in suicides like in Cork City, in South Carolina, USA and in Geneva [20, 21]. However, a literature search showed that, while men are known usually to commit suicide successfully, women have outnumbered men in non-fatal unsuccessful suicidal attempts [5, 20, 22, 23]. Mohanty et al., [24] revealed that males are the major sufferers $(54.15 \%)$ with average male to female ratio of 1.18:1. There was almost equal distribution among male $(53 \%)$ and females $(47 \%)$ in a study by Muninarayana et al., [25]. Our study is in contrast with Saisudheer and Nagaraja [26], Rastogi and Kochar [27] and Banerjee et al., [28] where female predominance was reported. Many studies have shown male predominance [29-33]. Males were four times more affected in Australia [34], whereas the male: female ratio was low in Hong Kong and Singapore [35]. Our findings were similar to that shown by Nadesan [36] in a study from Malaysia.

As observed in our study, the most vulnerable age group was 21-30 years $(40.98 \%)$ followed by $31-40$ years $(25.40 \%)$ which represent the most active and productive section of the society. Our study is in agreement with study of Muninarayan et al., [25], Udhayabanu et al., [16], Mohanty et al., [24], Rawat and Rodrigues [18], Kumar et al., [19], Bhosle et al., [37], Ahmad et al., [38] and Ajay Kumar et al., [39] where majority of the victims were in the age group of 21-30 years. The factors like frustration, failure to adjust with day to day stress and strain, sufferings, sudden emotional outburst, mental depression, abetment to suicides, drug addiction and failure in love affairs seem to compel victims to go for suicidal hanging at this age. In the present study, most suicidal hangings took place in younger age groups, $78.68 \%$ of them under the age of 40 years. Similar findings have been presented by Subedi et al., [40] and Rajarao et al., [41]. Most of the victims 116 (95.08\%) were Hindus followed by Muslims and Buddhist in equal proportion $(1.63 \%)$. The findings are in agreement with study by Ajay Kumar et al., [39] and Chaurasia et al., [42]. In India, a major part of the population follow Hinduism as their religion and this is due to Hindu predominance in the studied region.

In the present study, $86(70.49 \%)$ victims were married. Almost similar finding were reported by Udhayabanu et al., [16] (76.77\%), Rawat and Rodrigues [18] (55.44\%), Mohanty et al., [24] (76.04\%) 
Table 5. Ligature Material Used for Hanging.

\begin{tabular}{|c|c|c|}
\hline Ligature material & No. of cases & Percent \\
\hline Rope (synthetic, jute/sunn) & 53 & $43.44 \%$ \\
\hline Cbunni/dupatta & 49 & $40.16 \%$ \\
\hline Parna/nylon cloth & 06 & $4.91 \%$ \\
\hline Electric wire/clutch wire & 02 & $1.63 \%$ \\
\hline Plastic strap & 01 & $0.82 \%$ \\
\hline Shirt & 03 & $2.45 \%$ \\
\hline Muffler & 02 & $1.63 \%$ \\
\hline Salwar & 01 & $0.82 \%$ \\
\hline Towel & 01 & $0.82 \%$ \\
\hline Stole & 01 & $0.82 \%$ \\
\hline Niwar & 01 & $0.82 \%$ \\
\hline Rubber pipe & 01 & $0.82 \%$ \\
\hline Turban/pagri & 01 & $0.82 \%$ \\
\hline
\end{tabular}

Table 6. Distribution of Ligature Points of Hanging.

\begin{tabular}{|c|c|c|}
\hline Ligature point & No. of cases & Percentage \\
\hline Iron guider & 29 & $23.77 \%$ \\
\hline Ceiling fan & 28 & $22.95 \%$ \\
\hline Tree & 23 & $18.85 \%$ \\
\hline Ceiling hook & 16 & $13.11 \%$ \\
\hline Beams & 19 & $15.57 \%$ \\
\hline Ventilator & 3 & $2.45 \%$ \\
\hline Stairs & 1 & $0.82 \%$ \\
\hline Window & 1 & $0.82 \%$ \\
\hline Iron grill/rod & 2 & $1.63 \%$ \\
\hline
\end{tabular}

Table 7. Ecchymosis, White Glistening and Petechial Haemorrhages on Neck.

\begin{tabular}{|c|c|c|}
\hline Colour/Nature of ligature mark & No. of cases & Percentage \\
\hline \multicolumn{2}{|c|}{ Ecchymosis } \\
\hline Present & 44 & $36.06 \%$ \\
\hline Absent & 29 & $23.77 \%$ \\
\hline Not mentioned & 49 & $40.16 \%$ \\
\hline White glistening \\
\hline Absent & 43 & $35.24 \%$ \\
\hline Not mentioned & 20 & $16.39 \%$ \\
\hline Petechial haemorrhages \\
\hline Present & 57 & $48.36 \%$ \\
\hline Absent & 21 & $17.21 \%$ \\
\hline Not mentioned & 44 & $36.06 \%$ \\
\hline
\end{tabular}

and Ajay Kumar et al., [39] (63.9\%). This may be due to the fact that amount of stress carried by married persons in day to day life is more than the unmarried male or female which make them more vulnerable to commit suicide. Difference in suicidal hanging rates between rural and urban areas was also remarkable. In this study, $110(90.16 \%)$ cases were reported from rural area and 12 $(9.83 \%)$ from urban area. Our study is in agreement with study of Muninarayana et al., [25] who reported 75\% cases from rural background and $25.1 \%$ from urban background. Mohanty et al., [24] reported $74.19 \%$ cases from rural background and $24.42 \%$ from urban background. Rawat and Rodrigues [18] reported $72.28 \%$ cases from urban area and $27.72 \%$ cases from rural area.
This may be due to population of areas under study. In addition to this, lack of medical facilities and long distance from hospital in rural areas may explain that most of suicide attempts became completed suicide. However, western studies highlight that a high incidence of suicide has been observed among unmarried people. Our study is in agreement with a study by Arun et al., [20] who observed that there are probably different factors relating to marital or family life that are operating in the Indian culture. The institutions of marriage and family are given the utmost respect and are followed with great fervour in the Indian tradition, whereas 'live-in' relationships without marriage are more popular in the western world. In 101 (82.78\%) cases, data regarding the educa- 
Table 8. Incidence of Other Relevant Factors in Hanging.

\begin{tabular}{|c|c|c|}
\hline Factors & No. of cases & Percentage \\
\hline \multicolumn{3}{|c|}{ Dribbling of saliva } \\
\hline Present & 79 & $64.75 \%$ \\
\hline Absent & 43 & $35.24 \%$ \\
\hline \multicolumn{3}{|c|}{ Protrusion of tongue } \\
\hline Present & 79 & $64.75 \%$ \\
\hline Absent & 27 & $22.13 \%$ \\
\hline Not mentioned & 16 & $13.11 \%$ \\
\hline \multicolumn{3}{|c|}{ Seminal emission } \\
\hline Present & 37 & $30.32 \%$ \\
\hline Absent & 82 & $67.21 \%$ \\
\hline Not mentioned & 3 & $2.45 \%$ \\
\hline \multicolumn{3}{|c|}{ Urinary incontinence } \\
\hline Present & 52 & $42.62 \%$ \\
\hline Absent & 60 & $49.18 \%$ \\
\hline Not mentioned & 10 & $8.19 \%$ \\
\hline \multicolumn{3}{|c|}{ Faecal incontinence } \\
\hline Present & 61 & $50.00 \%$ \\
\hline Absent & 58 & $47.54 \%$ \\
\hline Not mentioned & 3 & $2.45 \%$ \\
\hline \multicolumn{3}{|c|}{ Blood from mouth and nostrils } \\
\hline Present & 36 & $29.50 \%$ \\
\hline Absent & 86 & $70.49 \%$ \\
\hline \multicolumn{3}{|c|}{ Cyanosis on mouth, tongue and face } \\
\hline Present & 63 & $51.63 \%$ \\
\hline Absent & 45 & $36.88 \%$ \\
\hline Not mentioned & 14 & $11.47 \%$ \\
\hline \multicolumn{3}{|c|}{ Clenching of teeth and fists } \\
\hline Present & 68 & $55.73 \%$ \\
\hline Absent & 41 & $33.60 \%$ \\
\hline Not mentioned & 13 & $10.65 \%$ \\
\hline
\end{tabular}

tion status of the victim was not available. 19 (15.55\%) cases were from the literate group, whereas $2(1.63 \%)$ were illiterate. In a study by Rawat and Rodrigues [18] 30.69\%, Udhayabanu et al., [16] 45.80\% and Mohanty et al., [24] 34.46\% victims were from illiterate group. While Muninarayana et al., [25] reported $87.6 \%$ cases from literate group and $12.4 \%$ from illiterate group.

In regards to occupational status, $40(32.78 \%)$ hanging cases belonged to housewives followed by students in $16(13.11 \%)$ and skilled labourer in $15(12.29 \%)$ cases in our study. In a study by Udhayabanu et al., [16] most of the victims were daily wagers (41.93\%) followed by housewives $(18.06 \%)$. Rawat and Rodrigues [18] reported maximum number of cases $(33.66 \%)$ from unemployed group followed by students (16.83\%). Muninarayana et al., [25] reported $36.3 \%$ cases from agriculturist followed by housewives $(22.3 \%)$. Kumar et al., [15] reported $22.7 \%$ cases from unemployed followed by housewives $(20.8 \%)$. Our study is in concurrence with Mohanty et al., [24] who reported 30.65\% cases of housewives followed by $25.81 \%$ cases of labourers among males. Bhosle et al., [37] revealed that hanging was more common in farmers $(30.12 \%)$ and labourers $(24.10 \%)$ followed by housewives
$(10.84 \%)$, students $(10.84 \%)$ and servicemen $(9.64 \%)$. These findings suggest that poverty, financial hardship, quarrel with spouse are playing major role in committing suicide.

As observed in our study, $45(36.88 \%)$ cases were reported in the months of January to April followed by May to August in 39 $(31.96 \%)$ and September to December in $38(31.14 \%)$ almost in equal distribution. This study is in agreement with the study of Rawat and Rodrigues [18] who have reported $47.52 \%$ cases in the months of January to April followed by $29.7 \%$ cases in the month of May to August and least in the month of September to December. Kumar et al., [15] reported maximum number of cases $(94.0 \%)$ in monsoon season. Our study is in contrast with a study by Ajay Kumar et al., [39] where majority of the cases were reported in summer season. Waghmare et al., [43] noticed that the summer and winter season contribute equal cases of suicide. Relatively fewer cases occurred in monsoon season. From these findings related to season and suicides, it can be concluded that suicides vary from season to season in different parts of the country and no typical seasonal variations in suicidal hangings were observed. 
In our study, $91(74.59 \%)$ victims preferred indoor sites (house, hotel, hostel, shop, office, cow shed and rented house) for hanging as compared to outdoor sites (forest, rivulet/nullah, fields and orchards) in 31 (25.41\%) cases which is consistent with the studies of Rawat and Rodrigues [18] (71.29\%), Mohanty et al., [24] (72.81\%), Kumar et al., [15] (94.0\%), Bhosle et al., [37] (69.88\%) and Udhayabanu et al., [16] (93.45\%). Patel et al., [44] reported that $93 \%$ cases were found from indoor places like home, workplaces, hotel room and custody barrack. Kumar et al., [19] reported that $92.21 \%$ preferred indoor locations of which maximum were residence. The reason for high indoor incidences may be easy accessibility of means and idea of victims not to be noticed by others and a fear of guilt in case of resuscitation.

With regard to precipitating/causative factors in committing suicide, physical illness, psychiatric illness/mental disorder were the major factors in $44(36.06 \%)$ cases followed by quarrel with spouse in $14(11.47 \%)$, drug addiction in $11(9.01 \%)$ and dowry dispute/ demand in $9(7.37 \%)$ cases in this study. Although, it has been observed that mental disorders constitute the largest risk factor for suicide. Our study is in agreement with the study of Rawat and Rodrigues [18] who noticed physical illness as the most common cause in $22.77 \%$ cases followed by poverty in $21.78 \%$ cases and drug addiction in $16.83 \%$ cases. Udhayabanu et al., [16] noticed family disputes like marital disharmony and quarrel with spouse in $52.25 \%$ cases followed by mental illness in $23.87 \%$ cases. Marital disharmony/quarrel with spouse $(29.96 \%)$ was the main cause behind hanging in a study by Ahmad et al., [38]. Economic distress, property dispute, dowry dispute and unemployment were other reasons of suicides in the present study.

Our study showed that rope (synthetic and jute/sunn) was the most common ligature material used in 53 (43.44\%) cases followed by chunni/dupatta in $49(40.16 \%)$ cases. Our findings are closely related to Bhosle et al., [37] (53.01\%), Pradhan et al., [4] (47.72\%) and Rawat and Rodrigues [18] (43.56\%). Synthetic saree (47.74\%) was the most common ligature material used for hanging in a study by Udhayabanu et al., [16]. Dupatta was the most common used ligature material in a study by Momin et al., [17] in $31.96 \%$ cases, Sharma et al., [45] in 30.90\% cases and Ahmad et al., [38] in $41.28 \%$ cases. The present study revealed that rope was the most commonly used ligature material as it is commonly available at home. As observed in the present study, other ligature materials used for hanging were cloth piece/parna, shirt, salwar, electric wire, muffler, stole as these are the basic things normally present at home, but are less conventional and reliable than rope.

The ligature point is a fixed structure to which the other end of the ligature material is tied to hang. In our study, iron guider was the commonest ligature point in $29(23.77 \%)$ cases followed by ceiling fan in $28(22.95 \%)$ and trees in $23(18.85 \%)$ cases. Our study is in contrast with studies by Ambade et al., [46] where trees were the commonest ligature points in hanging deaths followed by beams, ceiling hooks/fans and Vijayakumari [47] who reported ceiling fans, beams and grills as the common ligature points in hanging deaths. This is because the victims who had committed indoors suicide by hanging had an option of iron guiders, beams and ceiling hooks/fans as ligature points. Our study showed tree as the only ligature point used by victims for committing suicide outdoors.
Ecchymosis is a skin discoloration caused by bleeding underneath the skin. In our study, ecchymosis was present in $44(36.06 \%)$ and white glistening in $43(35.24 \%)$ cases. Petechiae is a small spot, especially on an organ caused by bleeding underneath the skin from external compression of the neck. In our study, petechial haemorrhages were present in $57(46.72 \%)$ cases. Our findings are consistent with a study by Rawat and Rodrigues [18] who reported petechial haemorrhages in $43.56 \%$ of cases.

Dribbling of saliva from the angle of mouth is supposed to be a sure sign of ante-mortem hanging. It could be because of congestion and mechanical stimulation of salivary glands consequent upon friction by ligature. In our study, dribbling of saliva was present in $79(64.75 \%)$ cases. Our findings are in agreement with Rawat and Rodrigues [18] where in $27.72 \%$ of cases, dried salivary stains were present over the angle of mouth, side of chin and front of chest. Sahoo et al., [48] observed dried salivary stains over the angle of mouth in $39 \%$ cases. Our findings are consistent with Patel et al., [49] who observed dribbling of saliva from angle of mouth opposite to knot in $71.25 \%$ cases. Dribbling of saliva was found in $38.37 \%$ cases of hanging by Shaikh et al., [50].

In our study, the protrusion of tongue was noticed in $79(64.75 \%)$ cases. This study is comparable with the study of Rawat and Rodrigues [18] where tongue was protruded in $50.49 \%$ cases. In a study by Sahoo et al., [48] tongue protrusion was seen in about $31 \%$ cases. The reason for this phenomenon could be due to the fact that constricting forces of the ligature causes upward pressure on the larynx and root of the tongue causing asphyxia as well as protrusion of tongue.

In the present study, the seminal fluid was seen in $37(30.32 \%)$ cases. Our findings are in agreement with Rawat and Rodrigues [18] where semen discharge was noticed in $10.89 \%$ cases and Patel et al., [49] who reported discharge of semen in $17.5 \%$ cases. Sahoo et al., [48] observed involuntary discharge including semen/ faeces in about $17 \%$ cases. In our study, faecal discharge was seen in 50\% cases. Sen Gupta [51] observed faecal discharge in 14.85\% cases, while faecal discharge was not seen by Rawat and Rodrigues [18]. Our study observed urinary incontinence in 52 (42.62\%) cases. Rawat and Rodrigues [18] noticed urinary incontinence in only $0.99 \%$ cases. Patel et al., [49] noticed discharge of urine/faeces in $13.75 \%$ cases.

In our study, cyanosis on mouth, tongue, face was noticed in 63 $(51.63 \%)$ cases. Rawat and Rodrigues [18] reported cyanosis of nail beds in $66.33 \%$ cases. Saiyed and Modi [52] found cyanosis of fingertips and nail beds of both hands in $94.59 \%$ cases which was the commonest finding. In the present study, blood from mouth and nostrils was present in $36(29.50 \%)$ and clenching of teeth and fists in $68(55.73 \%)$ cases. In a study by Shaikh et al., [50] dribbling of blood from mouth and nose was seen only in 1 case of hanging. Blood stained dried discharge and stains from nostril and face were observed in a case study by Bhullar [53].

\section{Conclusions}

Suicide is a major public health issue of the world especially in developing countries. Physical illness, psychiatric illness/mental disorder, quarrel with spouse, poverty, abetment to suicide and drug addiction are major causative factors which are directly or 
indirectly responsible for committing suicides. To overcome this problem, prior information and knowledge about suicidal behavior of persons, risk factors associated with it and early diagnosis of psychiatric disorders is required at familial and societal level. In addition, grooming of children at home to build a healthy child and make them mentally strong to face the harsh realities of life. Investigating agencies, media persons, social workers, health personnel, psychiatrics, non-governmental organisations (NGOs), political leaders, Governments and even the common man should play their role in identifying and tackling the underlying factors in the society to prevent the precious loss of life to family and society as well.

\section{References}

[1]. James R, Silcocks P (1992) Suicidal hanging in Cardiff- a 15 year retrospective study. Forensic Sci Int. 56(2): 167-175.

[2]. Gunnell D, Bennewith O, Hawton K, Simkin S, Kapur N (2005) The epidemiology and prevention of suicide by hanging: A systematic review. Int J Epidemiol. 34(2): 433-442.

[3]. Kamalakar D (2012) A new trend of suicides in India, Countercurrents. org., June 2016.

[4]. Pradhan A, Mandal BK, Tripathi CB (2012) Hanging: nature of ligature material applied and type of hanging according to point of suspension. Nepal Med Coll J. 14(2): 103-106.

[5]. Mohanty S, Sagu H, Mohanty MK, Patnaik M (2007) Suicides in India: a four year retrospective study. J Forensic Leg Med. 14(2): 185-189.

[6]. Gupta SC, Singh H, Trivedi JK (1992) Evaluation of suicide risk in depression and schizophrenics: a 2 year follow-up study. Indian J Psychiatry. 34: 298-310.

[7]. Rajagopal S (2004) Suicide pacts and the internet. BMJ. 329(7478): 12981299.

[8]. Birbal R, Maharajh HD, Clapperton M, Jarvis J, Ragoonath A, et al., (2009) Cyber suicide and the adolescent population: Challenges of the future? Int J Adolesc Med Health. 21(2): 151-159.

[9]. Thomas K, Chang SS, Gunnell D (2011) Suicide epidemics: The impact of newly emerging methods on overall suicide rates - a time trends study. BMC Public Health. 11: 314

[10]. Varnik P (2012) Suicide in the world. Int J Environ Res Public Health. 9(3): 760-771.

[11]. Vijayakumar L, Kumar MS, Vijayakumar V (2011) Substance use and suicide. Curr Opin Psychiatry. 24(3): 197-202.

[12]. National Crime Records Bureau (NCRB) Ministry of Home Affairs, Govt. of India NewDelhi report (2014), June 2016.

[13]. Suicide prevention (SUPRE) World Health Organization, June 2016.

[14]. Chauhan S (2015) Suicide cases surge $45 \%$ in 3 years in HP. Hindustan Times, Shimla.

[15]. Kumar C, Rana N, Goyal AK, Tanna J, Pathak A, et. al., (2015) Epidemiology of cases of hanging at Vadodara, Gujarat. IRPMS. 1(2): 23-26.

[16]. Udhayabanu R, Toshi S, Baskar R (2015) Study of hanging cases in Pondicherry region. IOSR- JDMS. 4 (7): 41-44.

[17]. Momin SG, Mangal HM, Kyada HC, Vijapur MT, Bhuva SD (2012) Pattern of ligature mark in cases of compressed neck in Rajkot region: A prospective study. J Indian Acad Forensic Med. 34(1): 40-43.

[18]. Rawat V, Rodrigues EJ (2015) Medico-legal study of hanging cases in north Goa. Int J Forensic Sci Pathol. 3(5): 110-118.

[19]. Kumar N, Sahoo N, Panda BB, Dutta A (2016) Demographic profile of hanging cases autopsied in Rims, Ranchi. GJRA-Global Journal for Research Analysis. 5(3): 119-121.

[20]. Arun M, Palimar V, Menezes RG, Babu YPR, Bhagavath P, et al., (2007) Autopsy study of fatal deliberate self - harm. Med Sci Law 47(1): 69-73.

[21]. Pridmore S (2011) Download of Psychiatry. Suicide: a broad view. 31: 1-17.

[22]. Shaw D, Fernandes JR, Rao C (2005) Suicide in children and adolescents: A 10 - year retrospective review. Am J Forensic Med Pathol. 26(4): 309-315.

[23]. Shields LBE, Hunsaker DM, Hunsaker JC (2005) Suicide: A Ten- year retrospective review of Kentucky medical examiner cases. J Forensic Sci. (3): 613-617.
[24]. Mohanty S, Sethi A, Patnaik KK, Mishra A (2014) Socioeconomic demographic study of suicide among the people in Southern town Berhampur of Odisha State (India). Austin J Forensic Science Criminol. 1(2): 1-6.

[25]. Muninarayana C, Anil NS, Kamath P, Reddy M, Ravi Shankar S (2013) A study of attempted suicides in Kolar, Karnataka. Int J Health Sci Res. 3(9): 35-39.

[26]. Saisudheer T, Nagaraja TV (2012) A study of ligature mark in cases of hanging deaths. Int J Pharm Biomed Sci. 3(3): 80-84.

[27]. Rastogi P, Kochar SR (2010) Suicide in youth: Shifting paradigm. J Indian Acad Forensic Med. 32(1): 45-48.

[28]. Banerjee G, Nandi DN, Nandi S, Sarkar S, Boral GC, et al., (1990) The vulnerability of Indian women to suicide- a field study. Indian J Psychiatry. 32(4): 305-308.

[29]. Saeed A, Bashir MZ, Khan D, Iqbal J, Raja KS, et al., (2002) Epidemiology of suicide in Faisalabad. J Ayub Med Coll Abbottabad. 14: 34-37.

[30]. Santhosh CS, Nawaz B (2013) Pattern of suicidal deaths at district hospital Davangere a cross-sectional study. J Indian Acad Forensic Med. 35(3): 233235.

[31]. Kanchan T, Menon A, Menezes RG (2009) Methods of choice in completed suicides: Gender differences and review of literature. J Forensic Sci. 54(4): 938-942.

[32]. Abdel Moneim WM, Yassa HA, George SM (2012) Suicide trends in Upper Egypt. J Forensic Sci. 57(5): 1247-1251.

[33]. Lahti A, Räsänen P, Riala K, Keränen S, Hakko H (2011) Youth suicide trends in Finland, 1969-2008. J Child Psychol Psychiatry. 52(9): 984-991.

[34]. Yip PS (1998) Suicides in Hong Kong and Australia. Crisis. 19(1): 24-34.

[35]. Yip PS, Tan RC (1998) Suicides in Hong-Kong and Singapore: A tale of two cities. Int J Soc Psychiatry. 44(4): 267-279.

[36]. Nadesan K (1999) Pattern of suicide: A review of autopsies conducted at the University Hospital, Kuala Lumpur. Malays J Pathol. 21(2): 95-99.

[37]. Bhosle SH, Batra AK, Kuchewar SV (2014) Violent asphyxia death due to hanging: a prospective study. J Forensic Med Sci Law. 23(1): 1-8.

[38]. Ahmad M, Rahman FN, Hussain MA, Chowdhury MH, Yasmeen BHN (2015) A medico-legal study of hanging cases at Dhaka Medical College. NIMCH J. 7(1): 110-114

[39]. Ajay Kumar S, Chandan V, Rudresh YC, Govindaraju HC, Gouda S (2013) Study of violent asphyxial deaths in Chitradurga district of Karnataka. IJBAR. 4(12): 868-871.

[40]. Subedi N, Chataut TP, Pradhan A (2015) A study of suicidal deaths in central Nepal. Eur J Forensic Sci. 2(2): 5-9.

[41]. Rajarao P, Anjannamma TC (2013) A study of suicidal deaths in married women in province of Telangana area, Andhra Pradesh (India). Int J Pharm Biomed Sci. 4(1): 37-39.

[42]. Chaurasia N, Pandey SK, Mishra A (2012) An epidemiological study of violent asphyxial deaths in Varanasi region (India) a killing tool. J Forensic Res. 3(10): 174.

[43]. Waghmare PB, Chikhalkar BG, Nanandkar SD (2014) Analysis of asphyxia deaths due to hanging. J Indian Acad Forensic Med. (36): 343-345.

[44]. Patel JB, Bambhaniya A, Chaudhari KR, Upadhyay MC (2015) Study of death due to compression of neck by ligature. Int J Health Sci Res. 5(8): 76-81.

[45]. Sharma BR, Harish D, Singh VP, Singh P (2005) Ligature mark on neck: how informative? J Indian Acad Forensic Med. 27(1): 1-6.

[46]. Ambade VN, Tumran N, Meshram S, Borkar J (2015) Ligature material in hanging deaths: The neglected area in forensic examination. Egyptian J Forensic Sci. 5: 109-113.

[47]. Vijayakumari N (2011) Suicidal hanging: a prospective study. J Indian Acad Forensic Med. 33 (4): 355-357.

[48]. Sahoo N, Kumar N, Panda BB, Datta A (2016) Significance of external findings in hanging cases during autopsy. IJBAR. 7(3): 119-122.

[49]. Patel AP, Bansal A, Shah JV, Shah KA (2012) Study of hanging cases in Ahmedabad region. J Indian Acad Forensic Med. 34(4): 342-345.

[50]. Shaikh MMM, Chotaliya HJ, Modi AD, Parmar AP, Kalele SD (2013) A study of gross postmortem findings in cases of hanging and ligature strangulation. J Indian Acad Forensic Med. 35(1): 63-65.

[51]. Sen Gupta BK (1965) Studies on 101 cases of death due to hanging. J Indian Medical Assoc. 45 (3): 135-139.

[52]. Saiyed MZG, Modi KK (2013) Retrospective study of post-mortem cases of hanging-a method of suicide. NHL J Med Sci. 2(2): 48-50.

[53]. Bhullar DS (2011) A rare case of hanging with black eye: a case report. J Punjab Acad Forensic Med Toxicol. 11(1): 47-51. 